\title{
Water Endowments and Virtual Water Trade
}

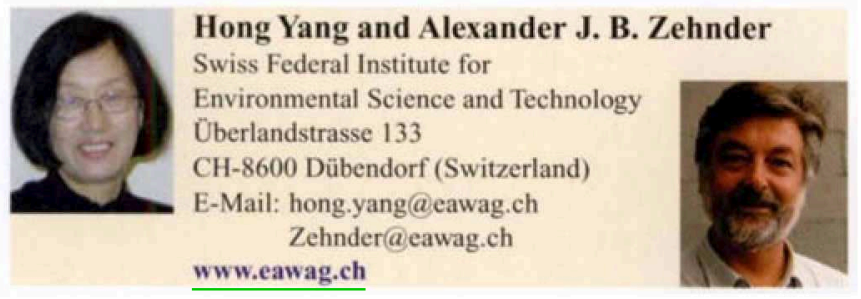

\section{Water Resources and Food Production}

Water and food are the fundamental elements for the survival of mankind. With agriculture being the largest water user among all sectors, there is an intrinsic relationship between a country's available water resources and the capacity of food production. During the past 40 years, a substantial growth in food production worldwide has been accompanied with a sharp increase in water use in agriculture, mainly for irrigation. With the continuous population growth and the escalating competition for water from other sectors, agricultural production has been faced with unprecedented challenges posed by water shortages and related problems ${ }^{[1-4]}$. Today, in many parts of the world, lack of water has been rapidly translated into constraints on food production. Most vulnerable are countries with unfavorable climatic conditions and high rates of population growth ${ }^{[s]}$. To cope with the rigidly augmenting food demand while water stress is intensifying, increasing amount of food must be imported. The food import that substitutes the local water demand for food production is termed 'virtual water'. Accordingly, the food trade is called 'virtual water trade' [6]. With a growing number of countries and regions in the world experiencing water scarcity, it is expected that virtual water trade will become increasingly important in the redistribution of global water resources and for food security in the countries where the resources are scarce.

While the scarcity of water resources on its own has been a limiting factor to food production, the ability of a country to bring its water resources into productive use also has a strong impact on its capacity of food production. In many poor countries, domestic production cannot meet the demand. This situation, however, is often not directly related to the amount of water resources per se. Typical examples are many subSaharan countries, where the low food production capacity and high incidence of food insecurity are often a result of the lack of agricultural investment in infrastructure and means of production ${ }^{[7]}$. Irrigation is limited and agricultural production is almost entirely reliant on rainfall, which is often erratic and unreliable ${ }^{[8]}$. Social and political conflicts, mismanagement and inappropriate economic development policies only exacerbate the problem ${ }^{[9]}$. For these countries, the inability to utilize their natural resources makes food import necessary. Failure to do so can only lead to starvation.

Food-exporting countries are, on the other hand, the exporters of virtual water. They are, therefore, the imperative players in the global virtual water trade. However, the current studies on the issue have focused overwhelmingly on the foodimporting countries ${ }^{[10-12]}$. Much less attention has been paid to the exporting countries concerning their water resource endowments and the efficiency in utilizing the resources. The understanding of the impact of overall economic development on the capacity of food production and food export is also far from adequate. Given the important role of foodexporting countries in the global virtual water trade, their water endowments and agricultural production deserve more attention in the studies of global water and food relations.

In this paper we investigate the status of individual countries in the global food trade system with respect to their water endowments and the capacity and efficiency in utilizing the resources for food production. Two issues are elaborated in detail: (1) the economic and environmental implications of irrigated and rainfed agriculture and (2) the distribution of the benefits of the global virtual water trade among different country groups with respect to the level of income. The analysis of these issues is aimed to gain an insight into the nature of water constraints on food production and the impact on food security. It can also help to reach a better understanding of the global virtual water trade patterns. The information will be useful for the development of food policies in the countries concerned and for the world community at large.

It is shown in the food balance sheet of the FAO database [13] that cereal grains are the principle staple food in most countries. Likewise, cereal grains are the dominant food commodities imported into food-deficient countries. In essence, cereal grains are the major carries of virtual water and the import has played a crucial role in redistributing the global water resources. The following analysis will focus on the relationship between water resources and cereal trade.

\section{'Green' and 'Blue' Water in Agricultural Production}

Based on the status of existence and the way of storage, water resources can be classified into two categories: 'blue' and 'green'. 'Blue water' refers to the water that exists in rivers, lakes and aquifers (that is, renewable groundwater). More specifically, 'blue water' is the sum of surface runoff - produced from the partitioning of precipitation (rain, hail, or snow) at the land surface - and groundwater recharge - produced from the partitioning of soil water in the soil profile ${ }^{[14]}$. The concept of 'green water' was first introduced by Falkenmark ${ }^{[15]}$, to distinguish it from the 'blue water'. In the literature, however, the definition of 'green water' differs somewhat among scholars. According to Falkenmark, 'green water' is the return flow of water to the atmosphere as evapotranspiration (ET) which includes a productive part as transpiration $(\mathrm{T})$ and a non-productive part as direct evaporation (E) from the soil, lakes, ponded areas, and from water intercepted by canopy surfaces ${ }^{[14]}$. However, the definition of 'green water' by Savenije ${ }^{[16]}$ includes only the productive part of the return flow - transpiration. Under this definition, the storage medium for 'green water' is the unsaturated soil. The total amount of 'green water' resources available over a given period of time equals the accumulated amount of transpiration over that period. Despite the difference in definition, it is clear that only the productive part of 'green water' is significant for agricultural production.

Irrigation typically uses 'blue water'. During the past four decades, irrigated areas for the world as a whole have nearly 

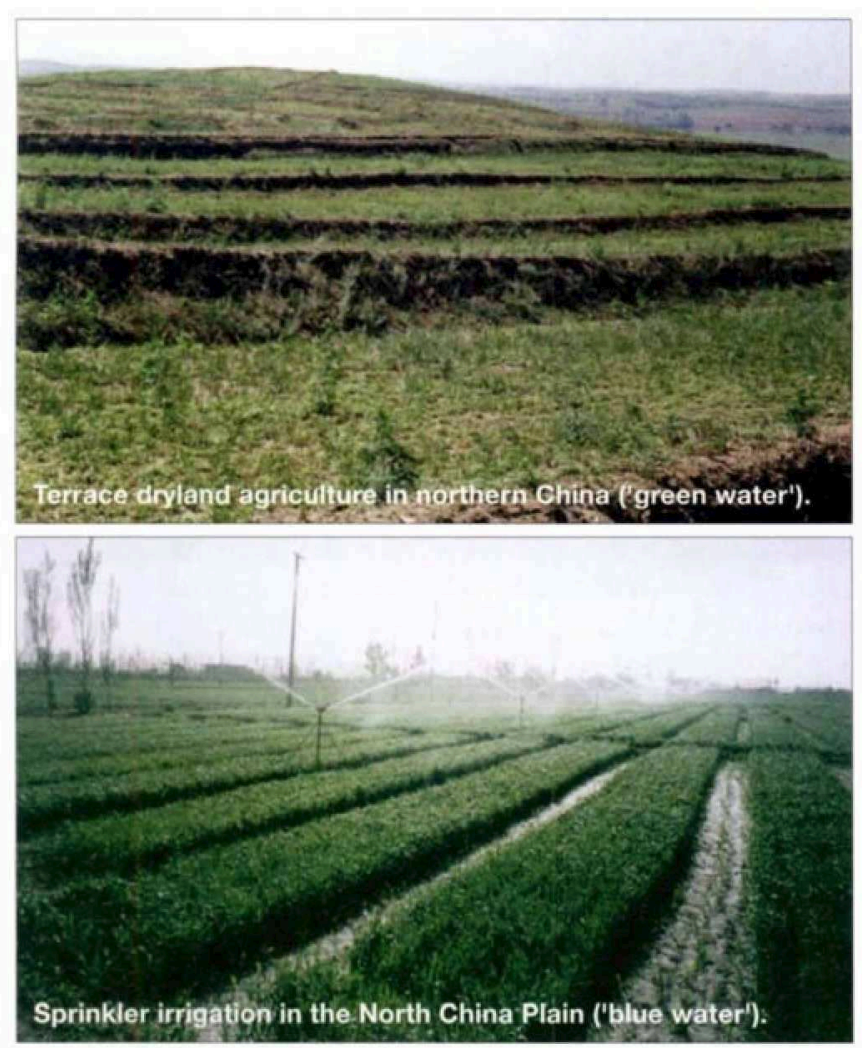

doubled in association with the 'Green Revolution' [13]. Today, the irrigated land accounts for about 17 percent of the total cropland of the world and produces over 40 percent of the world's food ${ }^{[4]}$. In water-scarce countries, the ratio of irrigated land to total cropland is generally higher because rainfall there is often not sufficient for crops to grow and irrigation is essential for attaining high yields.

While 'blue water' is important for food production, 'green water' remains the major resource in global food production. Currently, about 60 percent of the world staple food production is rainfed. Meanwhile, animal husbandry on pastoral land relies almost entirely on 'green water', and so does the production of wood from forestry ${ }^{[16]}$.

For the production of a kilogram of cereal grains, about I-3 cubic meters of water is required depending on the efficiency of water use in the production process ${ }^{[3,17]}$. This water can be directly from rainfall or from irrigation, or a combination of both. For food-exporting countries, therefore, the virtual water exported may be labeled 'blue' or 'green' depending on the water sources of the food production. In water-scarce countries, importing virtual water in the form of food effectively reduces the water demand that would otherwise be needed for producing the food at home.

It should be pointed out that the opportunity costs of the use of 'green water' and 'blue water' in agriculture are different and so are the environmental impacts. Broadly speaking, the opportunity cost of 'green water' is lower than that of 'blue water'. This is because the 'green water' comes free of charge from the rainfall. Such water is a 'free good'. Other plants (which often have lower economic value of water use than food crops) are the only major competitive user of this water. Hence, rainfed agriculture is rather efficient in terms of the opportunity cost of water resources. Meanwhile, the environmental impact of such water use is also relatively small because it generally does not change the distribution of natural water resources and the hydrological cycle. In con- trast, the opportunity cost of 'blue water' in agriculture is high since it has many functions and irrigation often yields the lowest economic value among all the functions ${ }^{[17]}$. Meanwhile, 'blue water' requires the facilities for storage and distribution before it can be used for irrigation. The environmental impact of such water use is often significant due to the changes in the natural courses of water flows and the distribution on the land surface. Moreover, in many areas of the world, irrigation has caused severe salinization, water logging and soil degradation [18]. Taking into consideration the opportunity costs and environmental impacts of the use of different types of water resources, it is clear that trading 'green virtual water' is overall more efficient and can be beneficial to the optimization of the international food market.

\section{A Global Analysis of \\ 'Blue' and 'Green' Virtual Water Trade}

Agricultural production and food trade in a country can be strongly influenced by its natural resource endowments, such as water and land. However, the financial capacity lays the foundation for a country to utilize its natural resources and invest in agriculture (including bringing water into irrigation). In the analysis of global virtual water trade patterns, therefore, it is necessary to take into account the level of incomes in different countries.

To proceed the analysis, countries are divided into four groups: high-income/cereal-exporting, high-income/cerealimporting, low-income/cereal-exporting, and low-income/ cereal-importing. Per capita GDP (gross domestic product) of USD 2000 per annum is used as a dividing-line to separate the high- and low-income countries. The choice of the dividing line considered the World Bank country income classification [19]. The low-income countries defined in this study include all the low-income and most of lower middle-income countries in the World Bank classification. The underlying idea of this division is to separate the countries with an ability to purchase food in the international market from those where such an ability is severely lacking or totally absent.

The ratio of irrigated areas to total crop areas indicates the dependence of a country's agricultural production on 'blue water'. A low ratio means that a country relies mainly on rainfall for agricultural production. In terms of opportunity cost, such an agricultural practice is more efficient. Conversely, a high irrigation ratio indicates a high dependency on 'blue water', which needs to be stored and delivered to the field through water facilities. In terms of opportunity cost, the use of 'blue water' for agriculture is less efficient. This is particularly so in water-scarce countries where alternative uses of water often generate much higher returns on investment.

Figure 1 shows the irrigation ratio against water resources in the four country groups. It can be seen that the number of exporting countries is small in both high- and low-income groups. In contrast, the number of importing countries is large in both income groups. This situation implies a delicate balance of the international food market.

Another manifest feature in Figure 1 is that the ratio of irrigated areas to total crop areas is small in the exporting countries, mostly below 20 percent. This situation indicates that food production in these countries is dominated by rainfed agriculture. A further inference is that the cereal-exporting countries generally export their 'green virtual water'. It is noted that the ratio in the low-income exporting country group is slightly higher than that in the high-income exporting country group, indicating a lower efficiency in the use of water resources. 


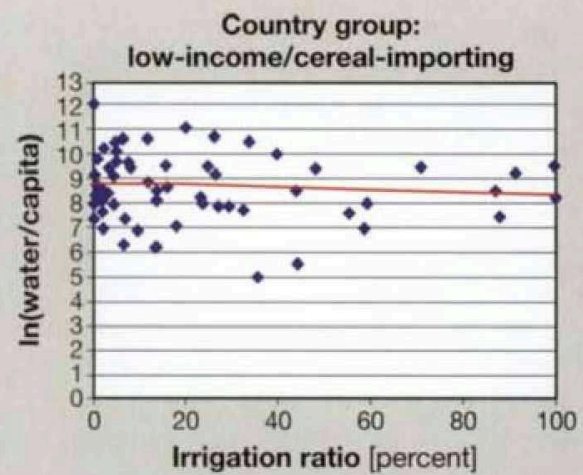

Country group:

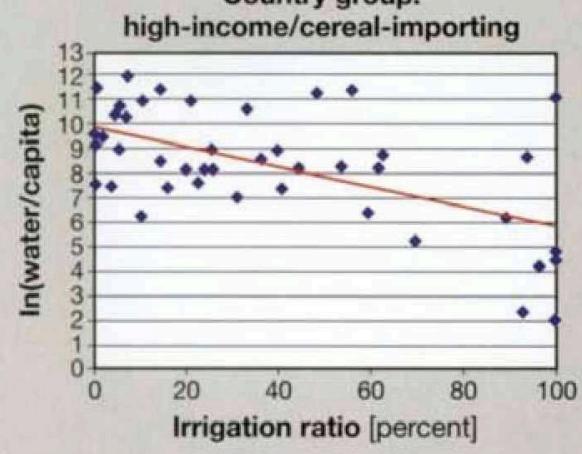

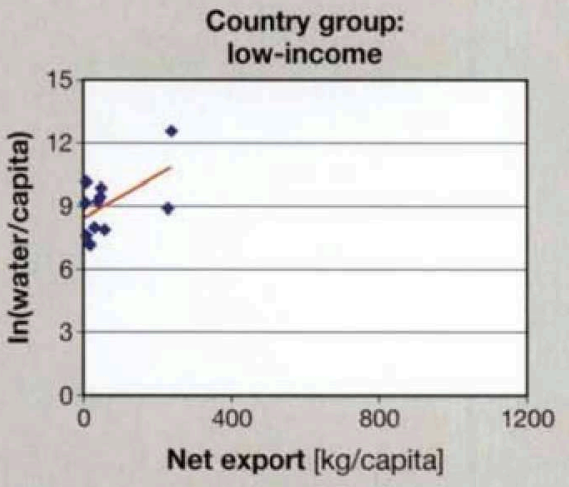

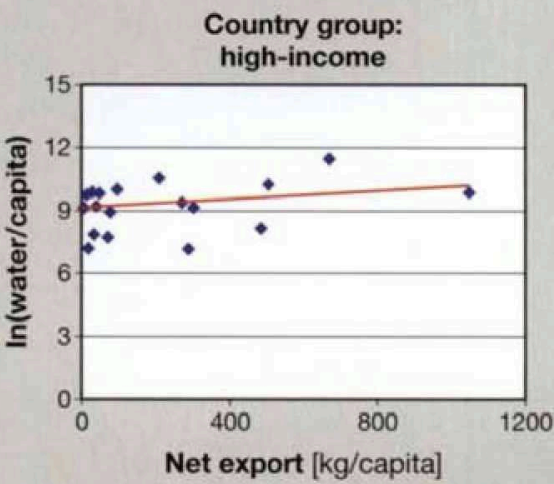

Figure 1.

Water resources versus irrigation ratio [13, 20]

$Y$-axis shows the natural logarithm value of per capita water resources in cubic meter at the country level.

$X$-axis is the irrigated areas as a percentage of the total crop areas at the country level The red solid line shows the linear relations between water resources and irrigation ratio.
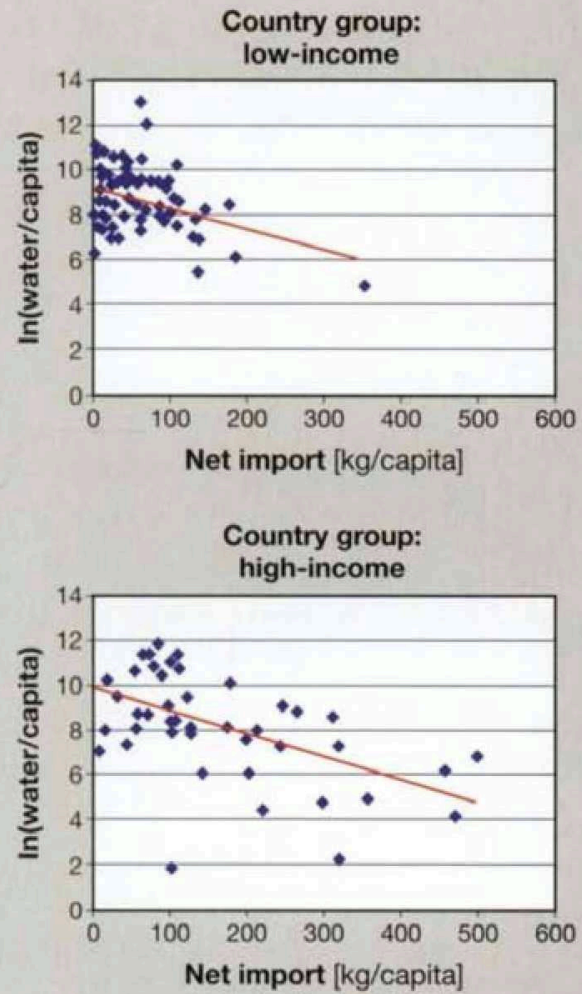

$\begin{array}{lccc}20 & 40 & 60 & 80 \\ \text { Irrigation ratio [percent] }\end{array}$
Country group:

Country group:

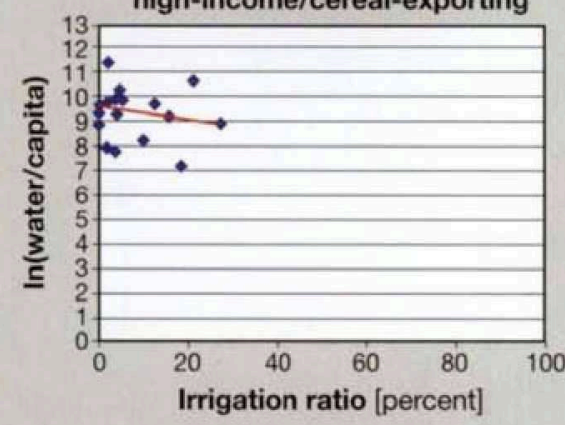

Figure 2.

Water resources versus net cereal import/export. $Y$-axis shows the natural logarithm value of per capita water resources in cubic meter at the country level.

$X$-axis is the per capita net cereal import/export in kilogram at the country level. The solid line shows the linear relations between water resources and net cereal import/export.
In the cereal-importing countries, the irrigation ratio varies widely but is overall higher than that in the cereal-exporting countries. This situation suggests that the cereal-importing countries have a higher dependence on 'blue water' in agricultural production. In the high-income cereal-importing country group, the strong downward trend-line indicates a significant inverse-relationship between water resources and irrigation ratio. This is not surprising given the fact that there are close links between precipitation, water resources and the need for irrigation at a river basin level, which is often the size of a country or several countries. The low rainfall generates a small volume of runoff on the one hand and makes agriculture more 
dependent on irrigation on the other. The strong downward trend-line in the high-income group suggests that the countries that have the financial ability to bring water into irrigation tend to do so. In the low-income countries, however, there is no clear trend in the irrigation ratio with respect to water resources. Most of the countries are located at the lower end of the spectrum of irrigation ratio, irrespective to their water resources. This situation is doubtless attributable to the lack of financial ability in these countries to bring water into irrigation.

For the countries that are unable to produce enough food to meet the local demand either because of the scarcity of natural water resources per se or the inability to utilize their water resources, importing virtual water is imperative for food security. Figure 2 depicts the virtual water trade patterns with respect to water resources in the four country groups.

For the cereal-exporting countries, there is a significant difference in the volume of export between the high-income and low-income groups. The volume of export per capita in the high-income countries is much larger than that in the low-income countries. This suggests that the high-income countries have been able to take the advantages of their abundant 'green water' in virtual water trade. For the low-income countries, the small volume of export suggests that they have not benefited significantly in such a trade.

For the high-income cereal-importing countries, there is a manifest relationship between the amount of water resources and cereal import. The lower the water resources, the larger the amount of cereal imports. For the low-income importing countries, however, the relationship is not clear. Most of the countries have a small amount of import. This is expected because low income means not only a low ability to bring water into agricultural use but also a low affordability to food import. As a result, most of the countries in this group endure food shortage and even starvation.

\section{Conclusion and Implications}

Several points can be drawn from the above analysis of water endowments, the ability to utilize the water resources and the patterns of global virtual water trade.

Firstly, the global cereal export is dominated by 'green virtual water'. This suggests an efficiency of the global cereal export in terms of water resources utilization. Most of the cerealexporting countries have abundant water resources. The export of cereal, a water-intensive commodity, is in line with their comparative advantage in water resources.

Secondly, there is an economic inefficiency in the allocation of water resources in the high-income cereal-importing countries. Lower water resources are associated with a higher ratio of irrigation, implying a higher proportion of water withdrawal for food production. Nevertheless, taking into consideration political and societal gains of domestic food production, the economic inefficiency in the water use may be, to some extent, a necessary trade-off in these countries. In the low-income importing countries, the overall low irrigation ratio and the lack of clear relationship to the water resources reflect their low ability to utilize the resources.

Thirdly, the current global virtual water trade is primarily between the high-income countries (Figure 2). Hence, the economic gains from the global virtual water trade are attained mainly by these countries. The low-income countries have a much less participation in the global virtual water trade. Apart from many other reasons, the low income and consequently the low ability to exploit the natural resources and invest in agriculture has impeded these countries' partici- pation. The lack of financial resources also deprived these countries' choice to purchase food from the international market when the domestic food supply is in shortage.

Lastly, while water scarcity is a constraint to food production, our analysis shows that food security is primarily determined by the level of income. For this reason, one should be cautious to expect miracles from the 'virtual water' concept in addressing the food security problems in poor countries [16]. Given the fact that many poor countries lack the necessary financial ability to either develop irrigated agriculture or purchase food from the international market, improving food security in these countries lies largely in rainfed agriculture. Therefore, greater efforts, particularly agricultural technologies and investment, should be made to the development of rainfed agriculture and the overall rural economy. From the viewpoint of water use optimization and environmental impact minimization, and given the increasing scarcity of global 'blue' water resources, more effectively utilizing 'green water' may also have to be a direction to which the world agriculture will pursue in the years to come.

\section{References}

[1] L. Brown, B. Halweil: "China's water shortage could shake world food security", World Watch No.7/8 (1998), www.worldwatch.org.

[2] S. Postel: "Water for food production - will there be enough in 2025?", BioScience 48 (1998) 629-637.

[3] H. Yang, A.J.B. Zehnder: "Water scarcity and food import - A case study for southern Mediterranean countries", World Development 30 (2002) 1413-1430.

[4] W. Cosgrove, F. Rijsberman: Making Water Everybody's Business World Water Vision, The World Water Council, Earthscan Publications, London (2000).

[5] R. Barker, C. Scott, C. Fraiture, U. Amarasinghe: "Global water shortages and the challenge facing Mexico", Water Resource Development 16 (2000) 525-542.

[6] T. Allan: Water, Peace and the Middle East-Negotiating Water in the Jordan Basin, Tauris Academic Studies, London (1996).

[7] P. Sanchez: "UC Berkeley expert in agroforestry and tropical resources", Campus News, 2002 World Food Prize, http://www.irinnews.org/report (2002).

[8] C.J. Vörösmarty, P. Green, J. Salisbury, R.B. Lammers: "Global water resources: vulnerability from climate change and population growth", Science 289 (2000) 284-288.

[9] B. Appelgren, W. Klohn: "Management of water scarcity - a focus on social capacities and options", Physics and Chemistry of the Earth B 24 (1999) 361-373.

[10] S. Postel: Pillar of Sand - Can the Irrigation Miracle Last?, Norton, New York (1999).

[11] J. Wallace: "Increasing agricultural water use efficiency to meet future food production", Agriculture, Ecosystems and Environment 82 (2000) 105-119.

[12] H. Bouwer: "Integrated water management - emerging issues and challenges", Agricultural Water Management 45 (2000) 217-228.

[13] Food and Agricultural Organization (FAO): World Agriculture Tawards 2015/2030, Summary Report, FAO, Rome (2002), www.fao.org.

[14] J. Rockström: "On-farm green water estimates as a tool for increased food production in water scarce regions", Physics and Chemistry of the Earth B 24 (1999) 375-383.

[15] M. Falkenmark: "Land-water linkages - A synopsis", in Land and Water Integration and River Basin Management, FAO Land and Water Bulletin, No. 1, p.15-16, Rome (1995).

[16] H. Savenije: "Water scarcity indicators: the deception of the numbers", Physics and Chemistry of the Earth B 25 (2000) 199-204.

[17] A.I.B. Zehnder: "Is water the first resource to control demographic development?", Proceedings of the Forum Engelberg, Food and Water: A Question of Survival, vdf Hochschulverlag, Zürich (1997), p. 85-98.

[18] M. Rosegrant, X. Cai, S. Cline: World Water and Food to 2025 Dealing with Scarcity, International Food Policy Research Institute, Washington DC (2002), www.ifpri.org.

[19] World Bank: The Little Green Data Book, World Bank, Washington DC (2000)

[20] World Resources Institute: Environmental Data Tables (Online Database, www.wri.org), Washington DC (2002). 